\title{
Physical Activity and its Relationship to Cardiovascular Risk Factors in Rural Japanese Men
}

\author{
Takeshi Miyagaki ${ }^{1}$, Hiroyasu Iso $^{2}$, Akihiko Kitamura ${ }^{3}$, Yoshihiko Naito ${ }^{3}$, \\ Tomoko Sankai', Takashi Shimamoto², Shinichi Sato ${ }^{3}$, \\ Masahiko Kiyama ${ }^{3}$, Masato Tanigaki ${ }^{3}$, Minoru lida ${ }^{3}$, \\ and Yoshio Komachi ${ }^{4}$
}

\begin{abstract}
Methods of quantifying physical activity in a population-based sample are needed to examine the relation of physical activity to cardiovascular diseases. We examined validity and reproducibility of an interviewer-administered physical activity questionnaire for men aged 40-59 years in a rural Japanese population. Validity was tested by comparing the estimate of physical activity from a 24-hour diary and maximum oxygen uptake from ergometer exercise test for forty-five men. There was no difference in the estimates of energy expenditure between the questionnaire and the 24-hour diary in each job classfication. Significant correlations were obtained between total activity estimated by the questionnaire and the 24-hour diary $(r=0.66)$ and between the total activity and maximum oxygen uptake $(r=0.30)$. Correlation coefficients between the test and retest at 1-2 year interval for 83 men were 0.67 for total activity, 0.62 for activity at work, 0.59 for leisure time activity and 0.24 for other activity. Using this questionnaire, energy expenditure in total physical activity was measured in 539 men aged 40-59 years living in a rural community of Akita, northeast Japan. Greater physical activity was associated with higher serum HDL-cholesterol levels, lower relative weight index. There was no significant association of physical activity with blood pressure levels, serum total cholesterol, cigarette smoking, and alcohol intake. Thus, greater physical activity was not always associated with lower coronary risk factors except for HDL-cholesterol. Prospective studies will be needed to clarify the relation of physical activity with cardiovascular disease in Japanese. $J$ Epidemiol, 1992 ; 2 : $97-104$.
\end{abstract}

physical activity, HDL-cholesterol, blood pressure, relative body weight, population-based study

Epidemiologic studies from the U.S. and European countries have provided evidence that higher physical activity, in particular, leisure time physical activity was associated with lower incidence and mortality of coronary heart disease ${ }^{1-4)}$. One of the major public health recommendations for sedentary Caucasians is an increase of physical activity ${ }^{5)}$. The situations may be different in Japanese because incidence and mortality from coronary heart disease was much lower in Japanese than in Caucasians ${ }^{6-8)}$. Stroke incidence and mortality was higher in Japanese than in Caucasians ${ }^{9,107}$. Relation between physical activity and stroke is not consistent. A prospective study of Japanese indicated a higher incidence of stroke in the highest qaurtile of energy expenditure ${ }^{11)}$ whereas studies of Caucasians showed an inverse relationship between physical activity and stroke ${ }^{12-14)}$, or no association ${ }^{15}$. These situations motivated us to develop a reliable questionnaire for qualifying physical activity and to apply it to a population-based sample for a future prospective study. In this study, we examined validity and reproducibility of a physical activity questionnaire, and using the questionnaire, examined energy expenditure and its relation with

Received October 8, 1992 ; Accepted November 22, 1992

${ }^{1}$ Labourer's Health and Welfare Association, Tokyo, Japan. ${ }^{2}$ Institute of Community Medicine, University of Tsukuba, Tsukuba, Japan. ${ }^{3}$ Department of Epidemiology and Mass Examination, The Center for Adult Diseases, Osaka, Japan. ${ }^{4} T h e$ Osaka Prefectural Research Institute of Public Health, Osaka, Japan

Address for correspondence: Hiroyasu Iso, Institute of Community Medicine, University of Tsukuba, 1-1-1 Tennodai Tsukuba lbaraki 305, Japan. 
cardiovascular risk factors in 539 middle-aged men of a rural community.

\section{SUBJECTS AND METHODS}

The surveyed population was men living in a rural community of Akita Prefecture, northeast of Japan. The major industry in the community is rice farming and light industry. A population survey was conducted for 539 men aged 40 to 59 years between 1986 and 1990. Response rate for the survey was $63 \%$. Detailed methods of population surveys were described elsewhere $^{16)}$. In brief, systolic and diastolic blood pressures were measured by trained physicians using a standard mercury sphygmomanometer on the right arm of seated participants after at least a 5-minute rest. Height in stocking feet and weight in light clothing were measured. Relative body weight was calculated from Minowa's standards based on medians of body weight distributions by height and sex for 5,086 healthy Japanese in 1960 to $1962^{17)}$. Minowa's relative weight index (RWI) was defined as a percent deviation of actual weight to standard weight. Skinfold thickness was measured at the right triceps and the right subscapular areas using a caliper. Values of skinfold thickness at the two sites were added up. Usual weekly alcohol consumption was determined by interview, and was recorded in a Japanese standard unit of alcohol beverage corresponding to $28 \mathrm{~g}$ of ethanol. Then, average daily alcohol consumption was calculated in grams of ethanol per day. The number of cigarette smoked per day was also interviewed. Blood lipids were measured using serum by the Center for Adult Diseases, Osaka. Total cholesterol was measured by enzymatic methods ${ }^{18}$. HDLcholesterol was measured after heparin-manganese precipitation using the Liebermann-Burchard method $^{19)}$. The laboratory was standardized by the Lipid Standardization Program, Center for Disease Control, Atlanta ${ }^{20)}$.

To estimate usual physical activity, an interview was conducted using standardized questionnaire (Appendix). The questionnaire was composed of frequency and time of (1) leisure time physical activity, (2) farming work, (3) work other than farming, and average time of sleeping during the past year. Using this questionnaire, average daily energy expenditure per weight was calculated according to the following formula :

Physical activity score $(\mathrm{kcal} / \mathrm{kg} /$ day $)=$

$0.9 * \mathrm{Bm} * T s+\Sigma[(R+1.2) * B m * T w]$

where in $B m=$ basic metabolic coefficient per minute and weight $(\mathrm{kcal} / \mathrm{kg} / \mathrm{min}), T s=$ average sleeping time per day $(\mathrm{min} /$ day), $T w=$ average time of each physical activity (min/day) and $R=$ relative metabolic rate of each physical activity. Basic metabolic coefficient was 0.015625 for men aged $40-49$ years and 0.015556 for men aged $50-59$ years $^{21}$. Relative metabolic rate was assigned 2.5 for farming work in average, 3.5 for non-farming manual work, 0.5 for clerical work, and 1 . 5 for other non-farming light work. Non-farming manual work was defined when men reported to be involved in carrying or lifting heavy stuff, handling a heavy cart, and/or using shovel and hammer. Nonfarming light work was defined as work at standing and/or driving a truck, other construction automobiles, and an ordinary car. Clerical work was defined as work at seat (see appendix).

To validate the physical activity questionnaire, 24hour diary of physical activity and ergometer exercise test was conducted for the subsample of 45 men. 24-hour diary of physical activity was determined by the modified method of Bouchard ${ }^{22)}$. The kind of major physical activity in every 15 minutes was recorded. If there was strong but short physical activity, such activity and duration time were also recorded. Energy expenditure during the 24 hours was calculated from the same formula used for the physical activity questionnaire. Relative metabolic rate for each physical activity was adopted from the reported data from Labor Science Institute ${ }^{23)}$. A collaborative study of physical activity among various geographic and occupational populations showed that the 24-hour diary method is feasible and provide a good estimate of physical activity for middle-aged Japanese $\operatorname{men}^{24,25)}$. Ergometer exercise test was done by a stepwise method within $85 \%$ of maximum pulse rates, and maximum oxygen uptake was estimated by the Astrand and Ryhming method ${ }^{26)}$. Maximum oxygen uptake was reported to reflect usual physical activity ${ }^{27)}$. Mean values of caloric expenditure from those two different methods and maximum oxygen uptake were calculated according to job classification: farmers, manual workers and clerical workers. Furthermore, correlations among these three variables were calculated.

Reproducibility of the physical activity questionnaire was examined by retesting 83 subsample one to three years apart. Mean energy expenditure was compared in each of classified jobs. Correlations between the two variables were also calculated.

The relation of physical activity with cardiovascular risk factors such as blood pressures, serum total cholesterol, HDL-cholesterol, alcohol intake and cigarette smoking was examined by computing mean values of cardiovascular risk factors according to the quartile of total energy expenditure. Tests of significance were conducted using analysis of variance. To test whether blood pressures and HDL-cholesterol varies by physi- 
cal activity after controlling for age and other covariates, the analysis of covariance was used. Then, multivariate-adjusted mean values of blood pressures and HDL-cholesterol were estimated according to the quartile of total energy expenditure. Changes of HDL cholesterol levels associated with a $10 \mathrm{kcal} / \mathrm{kg} /$ weight increase of total energy expenditure was also estimated using a multiple linear regression adjusting for age, relative weight index, alcohol intake and cigarette smoking. All p-values for statistical significance were two-tailed.

\section{RESULTS}

Validation of physical activity questionnaire

Table 1 shows mean values of energy expenditures estimated by the questionnaire and 24-hour diary, and mean values of maximum oxygen uptake by job. Energy expenditure was calculated for work, leisure time activity and other living activity, separately. Other living activity was defined as activity other than work or leisure time activity, such as eating, washing, bathing, watching TV and sleeping. According to both the questionnaire and 24-hour diary methods, mean energy expenditure at work and total energy expenditure were highest for farmer, intermediate for manual workers and lowest for clerical workers. The same was true for maximum oxygen uptake. There was, however, no difference in energy expenditure for leisure time physical activity and other living activity among the jobs. For each job, there was no difference in mean values of total energy expenditure, and energy

Table 1. Energy expenditure (mean \pm SD) estimated by the physical activity questionnaire, and the 24-hour diary, and maximum oxygen uptake (mean $\pm S D$ ) by job.

\begin{tabular}{|c|c|c|c|}
\hline & $\begin{array}{l}\text { Farmers } \\
(\mathrm{n}=10)\end{array}$ & $\begin{array}{l}\text { Manual } \\
\text { workers } \\
(\mathrm{n}=16)\end{array}$ & $\begin{array}{l}\text { Clerical } \\
\text { workers } \\
(n=19)\end{array}$ \\
\hline \multicolumn{4}{|c|}{$\begin{array}{l}\text { Energy expenditure estimated by the questionnaire } \\
(\mathrm{kcal} / \mathrm{kg} / \text { day })\end{array}$} \\
\hline Work & $34.1 \pm 8.0$ & $27.9 \pm 9.1$ & $13.4 \pm 2.1$ \\
\hline Leisure time & $0.2 \pm 0.5$ & $0.7 \pm 2.5$ & $0.7 \pm 2.1$ \\
\hline Others & $19.2 \pm 2.5$ & $20.1 \pm 2.2$ & $21.5 \pm 1.9$ \\
\hline Total & $53.5 \pm 5.5$ & $48.6 \pm 7.2$ & $35.6 \pm 3.0$ \\
\hline \multicolumn{4}{|c|}{$\begin{array}{l}\text { Energy expenditure estimated by the 24-hour diary } \\
(\mathrm{kcal} / \mathrm{kg} / \text { day })\end{array}$} \\
\hline Work & $36.2 \pm 5.8$ & $32.2 \pm 11.2$ & $19.4 \pm 5.4$ \\
\hline Leisure time & $0.1 \pm 0.3$ & $0.7 \pm 2.3$ & $0.7 \pm 1.6$ \\
\hline Others & $17.4 \pm 1.4$ & $18.4 \pm 4.9$ & $17.7 \pm 3.0$ \\
\hline Total & $53.7 \pm 5.1$ & $51.3 \pm 10.1$ & $37.9 \pm 3.8$ \\
\hline \multicolumn{4}{|c|}{ Maximum oxygen uptake $(\mathrm{ml} / \mathrm{kg} / \mathrm{min})$} \\
\hline & $42.0 \pm 4.4$ & $40.1 \pm 4.2$ & $37.2 \pm 6.4$ \\
\hline
\end{tabular}

Table 2. The Pearson correlation coefficients of energy expenditure estimated by the questionnaire with energy expenditure by the 24-hour diary and maximum oxygen uptake $(n=45)$.

\begin{tabular}{lc}
\hline \multicolumn{2}{c}{$\begin{array}{c}\text { Correlation with energy expenditure estimated } \\
\text { by the 24-hour diary }\end{array}$} \\
Work & $0.68^{* *}$ \\
Leisure time & $0.64^{* *}$ \\
Others & 0.14 \\
Total & $0.66^{* *}$ \\
Correlation with maximum oxygen uptake & 0.28 \\
Work & -0.01 \\
Leisure time & 0.11 \\
Others & $0.30^{*}$ \\
Total
\end{tabular}

${ }^{*} \mathrm{P}<0.05,{ }^{* *} \mathrm{P}<0.01$

expenditure at work, leisure time and other time between the questionnaire and 24-hour diary methods.

The Pearson correlation coefficients of energy expenditure estimated from the questionnaire with that estimated by 24-hour diary method, and maximum oxygen uptake were shown in Table 2 . There were strong correlations in energy expenditure between the questionnaire and 24-hour dairy method for total physical activity and physical activity at work and leisure time but not at other time. Correlations between energy expenditure by the questionnaire and maximum oxygen uptake were weaker, but the correlation between total energy expenditure and maximum oxygen uptake was moderate and was statistically significant.

Table 3 indicates mean values of energy expenditure estimated by test and retest of physical activity questionnaires. There was no difference in mean values of total physical activity, physical activity at work, leisure time and other time between the two studies.

The Pearson correlation coefficients in energy expenditure between the test and retest studies were shown in Table 4 . There were strong correlations between the repeated estimates for total physical activity and physical activity at work and leisure time. The correlation for the estimates of physical activity at other time was weak, but statistically significant.

Table 3. Energy expenditure (kcal/kg/day, mean \pm SD) estimated by the questionnaire in the test and retest studies $(\mathrm{n}=83)$.

\begin{tabular}{lrr}
\hline & \multicolumn{1}{c}{ Test } & \multicolumn{1}{c}{ Retest } \\
\hline Work & $22.6 \pm 11.4$ & $22.3 \pm 9.6$ \\
Leisure time & $0.5 \pm 0.7$ & $0.4 \pm 1.3$ \\
Others & $20.7 \pm 3.6$ & $20.8 \pm 2.8$ \\
Total & $43.9 \pm 8.7$ & $43.5 \pm 8.1$ \\
\hline
\end{tabular}


Table 4. The Pearson correlation coefficients of energy expenditure between the test and retest studies $(\mathrm{n}=83)$.

\begin{tabular}{ll}
\hline Work & $0.62^{* *}$ \\
Leisure time & $0.59^{* *}$ \\
Others & $0.24^{*}$ \\
Total & $0.67^{* *}$ \\
\hline
\end{tabular}

${ }^{*} \mathrm{p}<0.05,{ }^{* *} \mathrm{p}<0.01$

Physical activity and cardiovascular risk factors

Table 5 shows mean values of energy expenditure estimated by the questionnaire by age group. Between the ages 40-49 and 50-59, there was no difference in total physical activity, physical activity at work, leisure time and other time. Physical activity at work consisted of more than $50 \%$ of total physical activity whereas physical activity at leisure time less than $1 \%$.

Mean values of cardiovascular risk characteristics and the prevalence of current smokers by quartile of total energy expenditure are shown in Table 6. Mean systolic and diastolic blood pressures were higher in the lowest and the highest quartiles, but the difference among the quartiles did not reach statistical significance. Mean relative body weight index was lower in the third quartile than in other quartiles. Mean skin-

Table 5. Energy expenditure ( $\mathrm{kcal} / \mathrm{kg} /$ day, mean $\pm \mathrm{SD}$ ) estimated by questionnaire according to age group.

\begin{tabular}{lcrr}
\hline & $\begin{array}{c}40-49 \\
(\mathrm{n}=225)\end{array}$ & $\begin{array}{c}50-59 \\
(\mathrm{n}=314)\end{array}$ & \multicolumn{1}{c}{$\begin{array}{c}\text { Total } \\
(\mathrm{n}=539)\end{array}$} \\
\hline Work & $23.2 \pm 10.6$ & $24.6 \pm 10.9$ & $22.5 \pm 10.6$ \\
Leisure time & $0.4 \pm 1.4$ & $0.1 \pm 1.4$ & $0.3 \pm 1.3$ \\
Others & $20.7 \pm 3.1$ & $20.8 \pm 3.9$ & $21.2 \pm 3.7$ \\
Total & $44.3 \pm 8.9$ & $45.5 \pm 8.5$ & $45.0 \pm 8.7$ \\
\hline
\end{tabular}

fold thickness was lower in the upper two quatiles than in the lower two quartiles. Mean serum total cholesterol did not vary among the quartiles. Mean HDLcholesterol was lowest in the lowest quartile and progressively higher in the following two quartiles, and the increasing trend was saturated in the highest quartile. Mean alcohol intake was lower in the lower two quartiles and higher in the upper two quartiles although the difference was not significant. Mean number of cigarettes smoked and the prevalence of current smokers did not vary significantly among the quartiles.

Mean values of systolic and diastolic blood pressures according to the quartile of total energy expenditure were examined after controlling for age, relative weight index and alcohol intake. Adjusted mean values from the lowest to highest quartiles of physical activity were $131 \mathrm{mmHg}, 132 \mathrm{mmHg}, 131 \mathrm{mmHg}$ and $134 \mathrm{mmHg}$ for systolic $(\mathrm{p}=0.47)$ and $84 \mathrm{mmHg}, 83 \mathrm{mmHg}, 83 \mathrm{mmHg}$ and $84 \mathrm{mmHg}$ for diastolic $(\mathrm{p}=0.49)$. Although blood pressure levels were slightly higher in the highest quartile of physical activity, the difference was not significant.

Figure 1 presents mean values of HDL-cholesterol according to the quartile of total energy expenditute for men after controlling for age, relative weight index, alcohol intake and cigarette smoking. There was a clear dose-response relationship between physical activity and HDL-cholesterol $(\mathrm{p}=0.02)$. A multiple linear regression analysis indicated that an increase of physical activity for $10 \mathrm{kcal} / \mathrm{kg} /$ weight was associated with an increase of $3 \mathrm{mg} / \mathrm{dl}$ HDL-cholesterol.

Table 6. Cardiovascular risk characteristics (mean $\pm S D$ or prevalence) according to quartile of total energy expenditure $(\mathrm{kcal} / \mathrm{kg} /$ day) estimated by the questionnaire.

\begin{tabular}{|c|c|c|c|c|}
\hline & \multicolumn{4}{|c|}{ Energy expenditure quartile } \\
\hline & $\begin{array}{c}<38.1 \\
(\mathrm{n}=135)\end{array}$ & $\begin{array}{c}38.1-44.9 \\
(n=146)\end{array}$ & $\begin{array}{c}45.0-52.2 \\
(n=123)\end{array}$ & $\begin{array}{c}52.3+ \\
(n=135)\end{array}$ \\
\hline Systolic BP (mmHg) & $130 \pm 16$ & $130 \pm 17$ & $129 \pm 19$ & $132 \pm 20$ \\
\hline Diastolic BP (mmHg) & $84 \pm 11$ & $82 \pm 11$ & $81 \pm 11$ & $83 \pm 11$ \\
\hline Pulse rate (pulse/min) & $66 \pm 10$ & $64 \pm 10$ & $61 \pm 7$ & $63 \pm 9^{*}$ \\
\hline Relative weight index (\%) & $12 \pm 14$ & $13 \pm 14$ & $8 \pm 12$ & $12 \pm 13^{*}$ \\
\hline $\begin{array}{l}\text { Skinfold thickness (mm) } \\
\text { (triceps + subscapular) }\end{array}$ & $22 \pm 9$ & $21 \pm 9$ & $19 \pm 7$ & $20 \pm 8^{*}$ \\
\hline Total cholesterol $(\mathrm{mg} / \mathrm{dl})$ & $187 \pm 28$ & $186 \pm 29$ & $181 \pm 33$ & $185 \pm 34$ \\
\hline HDL cholesterol (mg/dl) & $55 \pm 15$ & $57 \pm 15$ & $64 \pm 14$ & $63 \pm 15^{* *}$ \\
\hline Alcohol intake ( $\mathrm{g} /$ day) & $45 \pm 33$ & $43 \pm 36$ & $50 \pm 32$ & $49 \pm 33$ \\
\hline $\begin{array}{l}\text { Cigarette smoking } \\
\text { (no./day) }\end{array}$ & $16 \pm 15$ & $15 \pm 15$ & $16 \pm 14$ & $14 \pm 13$ \\
\hline Current smorkers $(\%)$ & 66 & 64 & 71 & 60 \\
\hline
\end{tabular}

Difference among the quartiles of energy expenditure: ${ }^{*} p<0.05,{ }^{* *} p<0.01$ 


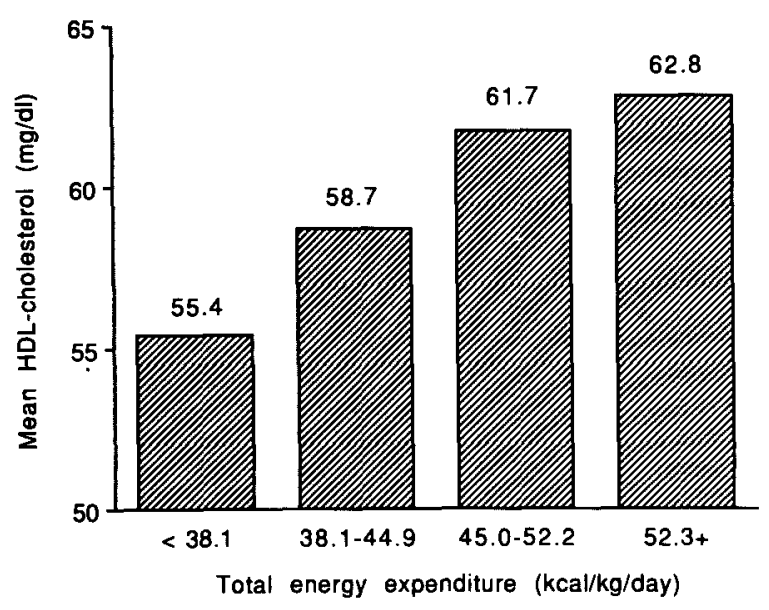

Figure 1. Adjusted mean values of HDL-cholesterol by total energy expenditure. Adjustment was done for age, relative weight index, alcohol intake, and cigarette smoking using analysis of covariance. $P$ value of the difference among the physical activity quartiles $=0.02$.

\section{DISCUSSION}

The present study showed that a simple questionnaire of usual physical activity was validated for a rural Japanese population where the major industry of farming is rice cultivation. Good validity was ascertained by comparing the estimate of total physical activity by 24-hour diary, and maximum oxygen uptake by submaximum ergometer exercise test. Good reproducibility was also obtained by a test-retest examination. The estimate of physical activity at work also had good validity and reproducibility. Leisure time physical activity was not correlated with maximum oxygen uptake, probably because this activity consisted of less than $1 \%$ of total physical activity. However, the estimate of leisure time physical activity showed good reproducibility. For Caucasians, leisure time physical activity was correlated well with maximum oxygen uptake, but physical activity at work was not $^{27,28)}$. The discrepancy between Japanese and Caucasians is probably due to a larger composition of physical activity at work and a smaller composition of leisure time physical activity in Japanese than in Caucasians.

There was a U-shaped pattern between physical activity and blood pressures although the difference in blood pressure levels among physical activity quartile was not statistically significant. From epidemiologic studies in the U.S. and European countries, low physical activity was associated with higher blood pressure levels in part due to overweight ${ }^{29,30}$. However, no studies in the U.S. and European countries reported an association of high physical activity with high blood pressures. Several epidemiologic studies in Japan suggested that a very high physical activity was associated with high blood pressure. Blood pressure levels were higher in rural Japanese than in urban population while physical activity level was higher in rural Japanese than in urban Japanese ${ }^{24)}$. A study for employees of Japan National Railroad indicated that blood pressure levels were higher in manual workers than in clerical workers ${ }^{31}$. These ecologic studies $^{24,311}$, however, did not adjust potential confounding factors such as sodium intake and alcohol consumption, and could not determine the causality between a very high physical activity and high blood pressures. Therefore, effects of very high physical activity on blood pressure levels in Japanese remain to be examined.

Mean relative body index was lower in the third quartile of total energy expenditure, and interestingly, was relatively higher in the highest quartile. Mean skinfold thickness, however, was relatively lower in the highest quartile as well as the third quartile of energy expenditure. Thus, men in the highest quartile of physical activity were assumed to have larger muscle mass rather than obesity compared to men in the lower two quartiles.

No association was observed between physical activity and serum total cholesterol which is consistent with previous studies ${ }^{32.33)}$. Serum total cholesterol is supposed to be affected by dietary fat intake such as saturated fatty acids, polyunsaturated fatty acids and cholesterol ${ }^{6,32}$.

HDL-cholesterol was positively associated with physical activity. After controlling for age, relative weight index, alcohol intake, and cigarette smoking, a dose-response between physical activity and HDLcholesterol became more evident. The positive association was reported from many epidemiologic studies in the United States ${ }^{34,35)}$ and European countries ${ }^{32,33)}$, but only from a few studies for urban Japanese employees ${ }^{25,36)}$. However, to our knowledge, no population-based study for rural Japanese reported this association. Therefore, the present study expanded the consistency of the positive association between HDL-cholesterol and physical activity in different ethnic groups. Experimental studies provided additional evidence on the causality between HDLcholesterol and physical activity. A moderate exercise program increased serum HDL-cholesterol by increasing $\mathrm{HDL}_{2}$ fraction ${ }^{37.38)}$. Physical activity raises activity of lecithin cholesterol acyltransferase (LCAT) in blood and lipoprotein lipase on endotherial cells of peripheral vascular wall, which transform $\mathrm{HDL}_{3}$ to 
$\mathrm{HDL}_{2}$ directly or indirectly, and inhibit activity of hepatic triglyceride lipase which transform $\mathrm{HDL}_{2}$ to $\mathrm{HDL}_{3}{ }^{38,39)}$.

Prospective studies from Caucasian populations showed that higher leisure time physical actively was associated with lower incidence or mortality of coronary heart disease ${ }^{1-4,40)}$. A prospective study in Japan ${ }^{11)}$ showed without statistical testing that labor intensity and working hours (but not total energy expenditure) were inversely associated with coronary heart disease, and that risk of stroke was higher in the highest qaurtile of total energy expenditure. Although a higher level of blood pressure in the highest qaurtile of physical activity is not statistically significant in the present study, previous studies of Japanese ${ }^{11,24,31)}$, suggested that very high physical activity increase risk of stroke in Japanese. Further studies will be needed to clarify the relation of physical activity with coronary heart disease and stroke in Japanese.

\section{ACKNOWLEDGEMENTS}

This study was supported in part by the Ministry of Education, and the Ministry of Health and Welfare as part of a collaborative nutritional study on prevention of ischemic heart disease in Japanese populations (Iida M, principal investigator, 1987-1989). Authors thank Mss Kishi M, Yamazaki $T$ and Ito $Y$ for the assistance of questionnaire survey.

\section{REFERENCES}

1. Paffenberger RS Jr, Hyde RT. Exercise in the prevention of coronary heart disease. Prev Med, $1984 ; 13: 3-22$.

2. Oberman A. Exercise in the primary prevention of cardiovascular disease. Am J Cardiol, 1985; 55 : 11D-20D.

3. Morris JN, Chave SPW, Adam C, et al. Vigorus exercise in leisure-time and the incidence of coronary heart disease. Lancet, $1973 ; 1: 133$.

4. Epstein L, Miller GJ, Stitt FW, et al. Vigorous exercise in leisure time : coronary risk factors and resting electrocardiogram in middle aged civil servants. Brit Heart J, 1976; 38: 403 .

5. Crow R, Blackburn H, Jacobs D, et al. Population strategies to enhance physical activity: the Minnesota Heart Health Program. Acta Med Scand, 1986; 711 (Suppl): 93-112.

6. Keys A. The diet : Coronary heart disease in seven countries. Circulation 1970; 42 (Suppl I) : 162-83.

7. Worth RM, Kato H, Rhoads GG, Kagan A, Syme SL. Epidemiologic studies of coronary heart disease and stroke in Japanese men living in Japan, Hawaii, and California: Mortality. Am J Epidemiol, 1975; 102: 481-90.

8. Pisa $Z$, Uemura $K$. Trends of mortality from ischemic heart disease and other cardiovascular diseases in 27 countries, 1968-77. World Health Stati, 1983; 35: 11-47.

9. Komachi $\mathrm{Y}$, Tanaka H, Shimamoto $\mathrm{T}$, et al. A collaborative study of stroke incidence in Japan: 1975-1979. Stroke, $1984 ; 15: 28-36$.

10. Aho K, Harmsen P, Hatano S, et al. Cerebrovascular disease in the community: results of a WHO Collaborative Study. Bulletin of the World Health Organization, 1980; 58: 113-130.

11. Tsuchida $\mathbf{M}$, Hayashi $\mathbf{M}$, Date $\mathrm{C}$, et al. A prospective cohort study on relationship of physical activity to subsequent incidence of stroke and ischemic heart disease. Bull Physical Fitness Reserch Institute, 1987 ; 65 (Suppl) ; 118128 (in Japanese with English abstract).

12. Wannamethee G, Shaper AG. Physical activity and stroke in British middle aged men. BMJ, 1992; 30: : 597-601.

13. Herman B, Leyten AC, Van Luijk JH, Frenken CW; Op de Coul AA, Schulte BP. An evaluation of risk factors for stroke in a Dutch community. Stroke, 1982; 13:334339.

14. Salonen JT, Puska P, Tuomilehto J. Physical activity and risk of myocardial infarction, cerebral stroke and death : a longitudinal study in Eastern Finland. Am J Epidemiol, 1982 ; 115 : 526-537.

15. Harmsen P, Rosengren A. Risk factors for stroke in middle-aged men in Goteborg, Sweden. Stroke, 1990; $21: 223-229$.

16. Shimamoto $T$, Komachi $Y$, Inada $H$, et al. Trends for coronary heart disease and stroke and their risk factors in Japan. Circulation, 1989; 79 : 503-15.

17. Minowa S. Study on stndard weights for Japanese adults : Charts of Minowa's relative weight index. Jpn J Med $1962 ; 24-28$ (in Japanese).

18. Siedel J, Hagele EO, Ziegenhorn J, Wahlefeld AW. Reagent for the enzymatic determination of serum total cholesterol with improved lipolytic efficiency. Clin Chem, 1983; 29 : 1075-1080.

19. Manual of laboratory operations, Lipid Research Clinics Program : Lipid and lipoprotein analysis. Bethesda, MD, US Department of Health and Welfare Publication 1974 : 1: 75-628

20. Nakamura M, Morita M, Yabuuchi E, et al. The evaluation of cholesterol and triglyceride standardization program by WHO-CDC. Rinsho Byori, 1982; 30: 325-332 (in Japanese).

21. Nutrition Section, Ministry of Health and Welfare: Nutrition Allowance for Japanese, 3rd Edition. Tokyo, Daiichi Shuppan Publishers, 1984, pp 25-49 (in Jpanaese).

22. Bouchard C, Tremblay A, Leblanc C, et al. A method to assess energy expenditure in children and adults. Am J Clin Nutr, $1983 ; 37: 4461-467$.

23. Numajiri K. Energy metabolism of physical activity. Tokyo, Research Institute of Labor Science, 1969.

24. Iida M. A nutritional study on prevention of ischemic heart disease in Japanese populations. Annual report of the research on cardiovascular diseases 1988. Osaka, National Cardiovascular Center, 1989, pp 321-323 (in Japanese with English abstract).

25. Naito $Y$, Iida $M$, Tanigaki $M$, et al. A questionnaire to assess usual physical activity in urban men. Public Helath 1991 ; $55: 485-490$ (in Japanese).

26. Siconolfi S, Cullinane E, Carleton R, Thompson P. Assessing $\mathrm{Vo}_{2}$ max in epidemiologic studies: modification of the Astrand-Ryhming test. Med Sci Sports Exercise, $1982 ; 14: 335-338$.

27. Taylor H, Jacobs D, Schucker B, et al. A questionnaire for the assessment of leisure time physical activities. J Chronic Dis, 1978 ; 31 : 741-755.

28. Debacker G, Kornitzer M, Sobolski J, et al. Physical activity and physical fitness levels of Belgian males aged 
40-55 years. Cardiol, 1981; 67: 110-128.

29. Blackburn H. Physical activity and hypertension. J Clin Hypertension, $1986 ; 2$ : 154-162.

30. Paffenbarger RS, Wing AL, Hyde RT, Jung DL. Physical activity and incidence of hypertension in college alumni. Am J Epidemiol, 1983 ; 117: 245-257.

31. Fukuda Y. Epidemiology of the occurence of cerebral stroke and heart attack with particular reference to influence of hypertension control and living conditions. Tokyo, Roudoigaku-Kenkyukai, 1978, pp 255-275.

32. Reggiani E, Bertolini S, Chiodini G, et al. Effects of physical activity and diet on lipemic risk factors for atherosclerosis in women. Int $\mathbf{J}$ Sport Med, 1984; 5 : 183-186.

33. Salonen JT, Hamynen $\mathbf{H}$, Leino $U$, Kostiainen E, Sahi $T$. Relation of alcohol, physical activity, dietary fat and smoking to serum HDL and total cholesterol in young Finish men. Scand J Soc Med, 1985; 13 : 99-102.

34. Haskell WL, Taylor HL, Wood PD, Schrott H, Heiss G. Strenuous physical activity, treadmill exercise test performance and plasma high-density lipoprotein cholesterol. The Lipid Research Clinics Program Prevalence Study. Circulation, 1980: 62 (Suppl); 53-61.
35. Castelli WP, Garrison RJ, Wilson J, et al. Incidence of coronary heart disease and lipoprotein cholesterol levels: The Framingham Study. JAMA 1986; 256: 2835-2838.

36. Koyama H, Ogawa M, Suzuki S. Relation between exercise and serum total cholesterol level. Jpn J Public Health, 1989 ; 36: 33-37.

37. Baker TT, Douglas A, Lei KY, Willcox KK. Alterations in lipid and protein profiles of plasma lipoproteins in middle-aged men consequent to an aerobic excercise program. Metabolism, 1986; 35: 1037-1043.

38. Stubbe I, Hansson P, Gustafson A, Nilsson Ehle P. Plasma lipoproteins and lipolytic enzyme activities during endurance training in sedentary men: changes in highdensity lipoprotein subfractions and composition Metabolism, 1983; 32: 1120-1128.

39. Haskell WL. The influence of exercise training on plasma lipids and lipoproteins in health and disease. Acta Med Scand, 1986; 711 (Suppl) : 25-37.

40. Leon S, Connett J, Jacobs DR Jr, Rauramaa R. Leisuretime physical activity levels and risk of coronary heart disease and death: The Multiple Risk Factor Intervention Trial. JAMA, $1987 ; 258: 2388-2395$. 
Appendix Physical activity questionnaire

Q1. Have you done any exercise during the past year? Yes or No. If yes, specify what kind of exercise, and its frequency and duration.

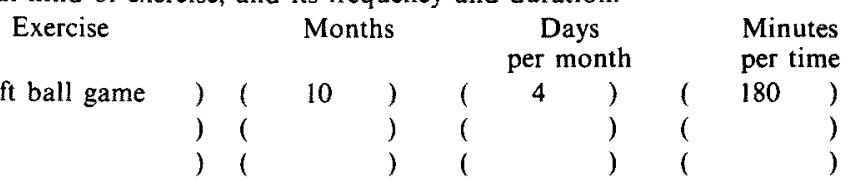

Q2. What kind of job have you engaged in mostly during the past year? Choose one.

(1) Farming only

(2) Farmrng and other jobs

(3) Work in companies or non-farmmg jobs

(4) Nothing particular

Q3. (Only for persons who choose (1) in Q1) Answer the following questions.

\# How many days per week are you usually engaged in farming?

\# How many hours per day are you usually engaged in farming? Exclude lunch time and tea break. hours and munites

\# How many hours per day do you sleep?

hours and minutes

Q4. (Only for persons who choose (2) in Q1) Answer the following questions

\# How many days per week are you usually engaged in farming?

days

\# How many hours per day are you usually engaged in farming? Exclude lunch time and tea break. hours and minutes

\# How many days per week are you usually engaged in non-farming jobs?

days

\# How many hours per day are you usualy engaged in non-farming jobs? Exclude lunch time and tea break.

\# How many hours per day do you sleep?

hours and minutes

\# What king of work do you do for non-farming job? Choose one or more.

(1) Carry or lift heavy stuff

(2) Handle a heavy cart

(3) Use shovel or hammer

(4) Drive a truck or other construction automobiles

(5) Drive an ordinary car

(6) Work at seat

(7) Work at standing

(8) Others (Specify:

Q5. (Only for persons who choose (3) in Q1) Answer the following questions \# How many days per week are you usually engaged in job?

\# How many hours per day are you usually engaged in job? Exclude lunch time and tea break.

\# How many hours per day do you sleep? hours and minutes

\# What king of work do you do for your job ? Choose one or more.

(1) Carry or lift heavy stuff

(2) Handle a heavy cart

(3) Use shovel or hammer

(4) Drive a truck or other construction automobiles

(5) Drive an ordinary car

(6) Work at seat

(7) Work at standing

(8) Others (Specify:

Q6. (Only for persons who choose (4) in Q1) Answer the following question.

\# How many hours per day do you sleep? 